\title{
Analysis of the Key factors for Successful Public Policy IMPLEMENTATION: A QUALITATIVE STUDY IN SLOVENIA
}

\author{
Žiga Kotnik ${ }^{1}$, Lan Umek ${ }^{2}$, Polonca Kovač ${ }^{3}$, \\ Dalibor Stanimirović ${ }^{4}$, Mirko Vintar $^{5}$
}

\begin{abstract}
This paper analyses the role and significance of the selected factors for the successful design and implementation of public policies in Slovenia and more broadly. Based on structured interviews and content analysis of the responses, we investigated the impact of predefined factors (i.e. strategic, institutional, normative, economic/financial, methodological/procedural, organisational/human resources/ICT support factors). The aim of the article is to analyse the case of Slovenia, to identify which factors contribute most to the successful design and implementation of public policies, and to provide a basis for comparison with similar countries or systems. The research findings imply several conclusions, particularly strategic factors, which have been identified as the most essential. The other findings are related to the lack of evaluation practice, the discontinuity of and early changes in government, which affect all aspects of policy execution and lead to poor intersectoral collaboration as well as insufficient and ineffective public debate. Not surprisingly, all of the identified hindrances are featured in the pertinent theories as necessary democratic dimensions of contemporary public governance. Contrary to the national context, the EU influence seems to expedite policymaking processes and contribute to the consistency of policies.
\end{abstract}

\section{Keywords}

Public Policy, Content Analysis, Good Governance, Evaluation, Strategic Factors

\section{Introduction}

Studies of public administration, law, political science, and economics disciplines have all highlighted that translating policy aims and objectives into practice is not as simple as might first appear (Howlett, Mukherjee and Woo, 2015). At present, it is widely

\footnotetext{
${ }^{1}$ University of Ljubljana, Gosarjeva ulica 5, 1000 Ljubljana, Slovenia. E-mail: ziga.kotnik@fu.uni-lj.si.

${ }^{2}$ University of Ljubljana, Gosarjeva ulica 5, 1000 Ljubljana, Slovenia. E-mail: lan.umek@fu.uni-lj.si.

${ }^{3}$ University of Ljubljana, Gosarjeva ulica 5, 1000 Ljubljana, Slovenia. E-mail: polonca.kovac@ fu.uni-lj.si.

${ }^{4}$ University of Ljubljana, Gosarjeva ulica 5, 1000 Ljubljana, Slovenia. E-mail: dalibor.stanimirovic@ fu.uni-lj.si.

${ }^{5}$ University of Ljubljana, Gosarjeva ulica 5, 1000 Ljubljana, Slovenia. E-mail: mirko.vintar@ fu.uni-lj.si.
} 
acknowledged that the nature of a public policy space, related socio-political context and its history are the fundamentals for successful design and implementation of public policies, programs, and projects (PPPPs) (Zito, 2015). PPPPs are henceforth often denoted as public policies, since public policies represent an umbrella term that also contains the subordinate notions such as programs and projects. Design and implementation of PPPPs are defined, but also determined by a diversity of different factors and players, where each player has its own interests, powers and resources. Common feature of all these policy players is that they all operate within an uncertain socio-political environment with limited timeframe, resources, knowledge and policy-relevant information (Bressers and O'Toole, 2005). Consequently, there are several challenges that affect successful implementation of PPPPs. Numerous inherent factors in different contextual areas influence the course of events in the policy arena(s), beside the pressure of international, national, regional or local policy actors, and that makes the policy-making process very complex and even more intriguing. Vertical and horizontal policy coherence represents an additional challenge, whereas coordination and management of public policies that have a crosssectoral character, is extremely difficult. Furthermore, there are usually no sufficient public appropriations for effective policy development and implementation, which often leads to ad-hoc solutions and improvisations. For the same reason, the comprehensive and detailed assessments and evaluations of expected effects or outcomes of public policies are rarely performed. On the political side of the public policy spectrum, ideological orientations, party interests and coalition agreement play a large role in the policy-making context, while professional and general public opinions are often overlooked and disregarded. This kind of mindset generously supported by the national cultural and political traditions, repeatedly leads to a lack of realistic and coherent strategic orientations and feasible action plans. A poorly structured and often arbitrarily guided policy-making process indirectly causes the ill-founded and unreasonable decisions, and subsequently reduces the interest of the professional and the general public in the public debate, deliberative process and issues under discussion. The communication between the public authorities and the general public is characteristically one-sided and rather limited, and thus ineffective. Therefore, the general public has habitually unrealistic expectations about certain policies and is all the more disappointed and dissatisfied after their implementation, which usually reflects in lower efficiency of the policies than anticipated.

It should be noted that so far, no holistic methodology has been developed in administrative, public policy or other related fields that could fully encompass the issues outlined above and the relevant processes concerning the conceptualization and implementation of public policies, especially adjusted to national specifics (such as history, administrative and legal traditions, or size of the country in question). On the other hand, given the importance of the concerns exposed, it is not surprising that several theories discretely address the pertinent factors that influence policy-making processes in the broader sense.

The article addresses above-mentioned gap and demonstrates the need for a comprehensive analysis concerning the design and implementation of public policies. The topicality of the article is reflected in the multidisciplinary of the topic, as required by such systemic societal problems. So far, studies have been without exception performed in the specific 
policy area(s), whereby this study offers a holistic comprehensive analysis of the key relevant factors for successful design and implementation of public policy, applicable extensively for all or most policy areas.

During the course of examination of the various relevant public policy theories, we extracted key factors: strategic, institutional, normative, economic/financial, methodological/procedural and organizational/human resources/ICT support, which we believe are key for the successful design, implementation and performance of the public policies in Slovenia. Consequently, we analysed the role, the nature and interdependence of these selected factors. The aim of the article is therefore to analyse the case of Slovenia, to determine which of predefined factors contribute most to the successful design and implementation of public policies, and to provide a basis for comparison with similar countries or systems. In line with the theoretical foundations, our paper primarily focuses on two interrelated research objectives:

* Analysis of the nature, role and significance of the selected factors for the successful design and implementation of public policies in Slovenia.

* Investigation of the interdependence of the selected factors and their impact (rank by relevance) on the performance of public policies.

Proposed research design is grounded in the good governance theory, the institutional theory, and the theory of rational choice. By linking policy design and policy-making with related theories, we try to fill the theoretical-methodological gap and contribute to the quest for a theoretical model that could explain policy-making dynamics in Slovenia and similar environments. The structure of the paper is as follows: firstly, a conceptual theoreticalanalytical framework based on the literature review of relevant public policy theories is discussed. Deriving from these findings, relevant factors for the successful public policies design and implementation are identified and selected. Then, methodological approach including research design, sample, data collection and data analysis is presented. Empirical results from qualitative content analysis based on structured interviews with the prominent experts are analysed next. Paper concludes with the relevant recommendations for the future successful design and implementation of public policies in Slovenia and broader.

\section{Theoretical-analytical framework of the research}

\section{Public policy environment}

Political leaders and policy makers, as well as bureaucrats shaping public policies, regularly face strategic decisions with uncertain future consequences due to the constant societal changes. The outcomes often depend on a variety of difficult to predict factors beyond their control (Volkery and Ribeiro, 2009). The reality of public policy decision-making is by definition met in conditions of high degree of uncertainty and complexity. In the last decades, design and implementation of PPPPs have been both contextually and methodologically, well elaborated in the academic literature (Howlett et al., 2015; Mintrom and Luetjens, 2017). Although a lot of research has been conducted so far, it has been without exception conducted in the specific policy area(s), which means that a systematic 
comprehensive analysis of the key factors influencing the process of public policy design and implementation, applicable widely for all or most policy areas, is still missing. The main focus of public policy studies, that is classified as a subsection of a wider discipline of political sciences (Cairney, 2013), has long been how to explain public policy processes and their outputs in the form of particular policy instruments. Researchers in this political science subfield study the formation, the processes and developments of public policy-making and public policy change, and aim to clarify why particular public policy approaches appear to be more successful than the other. In order to better understand the complexity of public policy processes, researchers regularly narrow down the focus on a subset of main public policy players frequently included in public policy formation in a given public policy area, like environmental policy or health policy. However, contemporary complex environment requires (more) interdisciplinary approach already at the lower and even more importantly at the higher governance levels (Raadschelders, 2011).

One of the frequently disregarded questions in political science and public administration is about the intriguing relationship between politicians and bureaucrats and how governance and administration are related to each other (Svara, 2006). Literature (May, Workman and Jones, 2008; Robinson, Caver, Meier and O'Toole, 2007; Workman, Jones and Jochim, 2009) assumes a greater role of the public administration (bureaucracy) in the earlier stages of policy-making process. Public administration is politically independent from the politics in the policy execution, although some degree of dichotomy among the two is necessary (Rahman, 2015). Bureaucracy is considered the instrument of government to prepare the legislation in order to address public challenges through the implementation of targeted policies and subsequent evaluation of public policy impacts (Kerwin and Furlong, 2018). However, in fact, bureaucracy often plays a pivotal role in shaping public policy environment and directing public policies, especially under certain conditions, which may arise during the interval between the old and the newly elected government, lack of national strategies and plans, upon the arrival of inexperienced political structures on high political positions, or from covert ideological / political action of the bureaucracy. These problems can be especially acute in politically unstable countries with a short democratic tradition and weak state institutions. Such a practice can be very perilous, as it can escalate to a significant democratic deficit and other structural anomalies in the functioning of the government bodies. The search for the balanced role of the bureaucracy is delicate and must be supported by different systemic measures, such as; adequate legislation, the existence of strategic guidelines and action plans in the priority areas of state action, quality functioning of institutions, constant and comprehensive political (parliamentary) oversight, effective dialogue with civil society and non-governmental organisations, etc.

\section{Public policy cycles}

In the 1950s the theory of public policy cycles was developed by Harold Lasswell in the USA, where he proposed an innovative idea by describing public policy science as being multidisciplinary, problem-solving and explicitly normative. Nowadays, there is a consensus among academia that public policy cycle consists of five stages (Howlett 
and Ramesh, 2003), namely: (1) agenda-setting, (2) public policy formulation, (3) public policy decision-making, (4) public policy implementation and (5) public policy evaluation. Though all five are significant, three of them - agenda-setting, formulation and implementation - are vital to understanding public policy cycles. However, for successful implementation of public policies and their perpetual adaptation, it is of the upmost importance to carry out all phases of the public policy cycle, including evaluation with correctional measures, in order to follow sound public governance principles, again on various political as well as administrative levels (Ongaro and van Thiel, 2018).

\section{Good governance, institutional and rational choice theories and key performance factors}

Good governance theory is becoming the dominant political theory to analyse contemporary political affairs (see Keping, 2018, Ongaro and van Thiel, 2018, etc.). It denotes a legitimate, accountable, and effective way of obtaining and using public powers and resources in the pursuit of widely-accepted goals (Johnston, n.d.), and refers to public administration process that maximises public interest. Good governance comprises the active cooperation between citizens and the government, where the key to its success lies in the stakeholders participating in public debate and deliberation, and ensuing in public policy-making. In practice, good governance is established within a network among the government bureaucracy, interest groups, business, and civil society (Keping, 2018; Kooiman, 2003). Cooperation and engagement of multiple stakeholders contributing different views in political arena results in more robust and popularly legitimate public policies serving needs and expectantly benefiting the largest possible number of citizens. Besides scholars, numerous international organisations follow at least some of the respective principles outlined in the good governance theory, such as United Nations, OECD, IMF, and European Commission. A set of principles from this theory relies primarily on: participation, rule of law, transparency, responsiveness, consensus orientation, equity, effectiveness and efficiency, accountability and strategic vision. Due to the feasibility of the research, the limitations of the selected qualitative methodological approach, and, in the light of the priority deficiencies identified in the Slovenian national context, in this paper we focus on the impact of the following factors stressed out in the good governance theory, namely: rule of law (normative factors), effectiveness and efficiency (methodological/procedural factors), and strategic vision (strategic factors).

The rule of law, as one of the nine essential principles of good governance, implies that the law is the supreme principle in public administration, which ought to be respected by all government officials and citizens. The instant goal of the rule of law is the management of social affairs, regulation of citizen's behaviour, and maintenance of normal order in social life. The definitive goal of the rule of law is to protect citizens' political rights like equality or freedom. In this view, the "rule of law" is an elementary prerequisite of good governance, that could be impossible without a firm legal system, including the respect for the law and a social order based on the law (Graham, Plumptre and Amos, 2003; Kovač and Bileišis, 2017). The role of the legal factors is in defining the relevant values and determining responsibilities in pursuing the public interest (Bennett and Howlett, 1992). 
Strategic elements in a form of strategies, action plans, regulations, directives, and recommendations, etc. formulate practical instruments that direct the functioning of institutions and stakeholders, and may be used to create synergies between all participants by working together on a local, regional, national or European level (Council of Europe, 2018; European Union, 2018). The establishment of a strategic framework for public policies helps to ensure that individual policies are consistent with overarching government goals and long-term priorities (Bache and Flinders, 2004). The IFAC study (IFAC, 2004) demonstrates that strategic factors are very important, but not sufficient within government public policy process when determining the success or failure of particular policy. To offer guidance, the European Union adopts a number of strategic and legal documents for all major areas (EC, 2015; European Parliament and the Council, 2016). In our research these documents are considered as strategic factors, and are more or less consistently followed at national level (e.g. (MJU, 2015)). In the last years, however, for various reasons some EU Member States have been producing different strategic documents of doubtful quality (e.g. MJU, 2015) mainly due to requirements (and some recommendations) of the European institutions and not due to their own initiative.

Methodological/procedural factors are presented in this paper in association with effectiveness and efficacy as one of the characteristics of good governance theory (UNDP, 1997). Effective and efficient governance involves existence of measurable public policy objectives, indicators and target values. In pursuit of pre-determined public policy objectives, we must also consider the processes that enable the implementers to easily follow instructions when executing their agenda. Policy-makers, therefore, need to use adequate methodological tools in order to properly execute all five stages of public policy cycle. As defined and understood in this paper, procedural/methodological factors are translated into the subcategories, consisted of the following activities concerning the public policy cycle: how much emphasis is given to the analysis and impact assessment of the particular public policy, existence of relevant field related indicators, comprehensive and systematic approach to decision-making process(es), preparation of alternative solutions, implementation, monitoring and evaluation of public policies, and concrete actions and general development of public policy(ies).

Not only the environment determines the normative expectations for particular public policy, but institutions themselves are also able to form the expectations and perceptions of the environment (Scott, 1995). Designing and implementing public policies are engagements where substantial institutional work is essential for their achievement. Institutional theory explains public policy changes promoted by institutions where rules, norms, routines and environment become guidelines for accepted behaviour. Institutions, in this sense, are the "rules of the game" which govern social exchanges undertaken by organisations and individuals (North, 1990). Institutional theory deepens the understanding about the normative, coercive, and mimetic institutional dynamics that shape decisions of the government about the adoption and implementation of particular public policy. As a result, organisations that meet the environment's expected characteristics receive legitimacy and prove worthy of resources by community and the broader society (Toma, Dubrow and Hartley, 2005). Rather than optimising their internal 
processes and decisions, organisations are inspired by their peers for hints and cues to achieve appropriate behaviour and decision making (Marquis and Tilcsik, 2016). In public policy context, institutional theory is defined as a "policy-making that emphasizes the formal and legal aspects of government structures" (Kraft and Furlong, 2007). In this way, institutional environment may have a powerful effect on the development of formal structures in an organisation that are frequently more profound than market pressures (DiMaggio and Powell, 2000; Meyer and Rowan, 1977). Institutional factors are defined as a degree of embeddedness of responsibility/jurisdiction for the implementation of a particular public policy in hierarchical structure of public administration. Furthermore, Stoker (Stoker, 2006) claims that closed (public) institutions and ambiguity about where ultimate responsibility for decisions rests create a major problem of accountability for decision making. Consequently, an inadequate institutional placement often also means weak competencies and jurisdiction, poor project management and control, which can seriously affect the success of the public policies implementation.

Economic/financial factors play an important role in the rational choice theory. The rational choice theory is highly influenced by economics and assumes that in decision-making individuals are rational actors that seek to maximise their welfare or further their selfinterest (Kraft and Furlong, 2007). The rational choice, also called public choice theory, focuses on public or collective choices as opposed to the private choices of individuals analysed by conventional micro-economic view (Buchanan, 1999). The foundational assumption of the rational choice theory is the underlying belief that homo economicus equals homo politicus. The rational choice theory states that self-interest is the cornerstone of political behaviour where economics can provide rules for rational consumers and producers (Downs, 1957). Economic and financial aspect plays an important role in the design and implementation of PPPPs, whereas execution of PPPPs including costs for qualified human resources is critically dependent on available funding (Laforet, 2011). Financial capital is one of the resources required by organisations (government institutions) to start, operate or grow and one of the main prerequisites for technological innovation (Lecerf, 2012). In the area of economic/financial factors, we are largely interested in how the structure and financial resources influence the performance of public policy design and implementation. Further, we are interested whether the economic/financial factors are predominant in pursuing individual development policy strategic objectives.

Having available expert human resources within public organisations, combined with adequate human resource strategy is crucially important for the public policy-making process. Human resource management addresses the people-flow subsystem, its objectives, human resources structure, competences, rewarding and interpersonal relations among others (Bamberger, Meshoulam and Biron, 2014). Human factors have also proven to be a significant force for or against the successful implementation of policies (Al-Mamari, Corbitt and Oyaro Gekara, 2013). On the other side, for reaching the maximum potential of human resources, it is important that the entire public policy-making cycle is well arranged, streamlined and controlled (Minor, Bergmann and Görg, 2014), which depends on organisational factors. Another important factor is the availability of information and communication technologies (ICTs) to support design, implementation and execution of 
public policies (Woolthuis, Lankhuizen and Gilsing, 2005). Literature review (Gichoya, 2005) demonstrates a large deficit concerning ICT support in the processes of public policy-making. Organisational/human resources/ICT support factors were combined into one multifaceted factor in our analysis.

Table 1: Theories and major factors for successful design and implementation of public policies (in Slovenia)

\begin{tabular}{|c|c|c|}
\hline Public policy theories & $\begin{array}{l}\text { The list of selected key } \\
\text { factors affecting } \\
\text { PPPPs cycle }\end{array}$ & Description \\
\hline \multirow{3}{*}{ Good governance theory } & Strategic & $\begin{array}{l}\text { The use of strategic approach, i.e. } \\
\text { existence of general and policy specific } \\
\text { strategies, action plans and other long } \\
\text { term policy documents, both } \\
\text { national/international and the EU related }\end{array}$ \\
\hline & Normative & $\begin{array}{l}\text { Legal/regulatory framework available to } \\
\text { enforce PPPPs design (e.g. legislative } \\
\text { process or RIA) and implementation }\end{array}$ \\
\hline & Methodological/procedural & $\begin{array}{l}\text { Methodological approach, principles, } \\
\text { procedures, techniques and tools used for } \\
\text { the PPPPs design and implementation }\end{array}$ \\
\hline Institutional theory & Institutional & $\begin{array}{l}\text { Clear, available and authorised } \\
\text { institutional framework within } \\
\text { governmental structures for } \\
\text { policy-making and the implementation } \\
\text { of PPPPs under observation }\end{array}$ \\
\hline \multirow[t]{2}{*}{ Rational choice theory } & Economic/financial & $\begin{array}{l}\text { Financial resources: availability, structure, } \\
\text { sources }\end{array}$ \\
\hline & $\begin{array}{l}\text { Organisational/human } \\
\text { resources/ICT support }\end{array}$ & $\begin{array}{l}\text { Organisation and/or existence of special } \\
\text { policy unit in the centre of the } \\
\text { government and ministries, HRM, ICT } \\
\text { support }\end{array}$ \\
\hline
\end{tabular}

Source: authors based on own analysis

Attempts to draft a roadmap for design and implementation of public policies have raised numerous questions about the appropriate government strategy, organisational structure, the role and power of the government, financial appropriations, and suitable methodology framework that does the job. Those areas remain some of the most interesting questions in public policy research. Scholars in the field have largely borrowed theoretical themes from political, law, social, organisational, economic, and management sciences to explore and clarify the phenomenon of public policy design and policy-making through the lens of such established theories. Since there is no unified overarching theory to cover all the relevant factors for successful design and implementation of PPPPs, the paper presents 
a selection of relevant public policy theories that in our understanding most suitably embrace the nature, role, significance and interdependence of the observed factors. In this paper, we applied these public policy theories to examine the entire notion of design and implementation of PPPPs in Slovenia. On this theoretical basis, we have defined strategic, institutional, normative, economic/financial, organisational/human resources/ICT support and methodological/procedural factors, which according to underlined theories; have an effect on the design and implementation of public policies, and development of programs, and projects (Table 1).

The list of selected key factors affecting PPPPs cycle is based on the political and economic position of Slovenia and its membership in the EU (since 2004), relatively small size of the country, its transitional context including the post-socialist legacy and Rechtsstaat, and consequent policy gaps in the implementation thereof, etc. (Kovač and Bileišis, 2017; Raadschelders, 2011; Vintar, Aristovnik and Klun, 2018). Nevertheless, as explained further in the methodology section, we have kept open the possibility to discover and identify potential new factors, which could have a critical impact on policy-making cycle.

\section{Methodological approach}

\section{Research design}

The paper employs an explanatory and exploratory content analysis research design supported by the broad review of the literature and investigation of numerous sources containing problem-related content. Content analysis method was applied on structured interviews and object-oriented discussions with the prominent experts in the field. The research on the role and significance of the selected factors for successful design and implementation of public policies in Slovenia, and their interdependence and impact on the performance of public policies was conducted from February to September 2017. A selection of the research method was adapted to the particularities of the research problem and their implications (Kotnik and Kovač, 2018; Thomas, 2006; Yin, 2017). Since this research is largely exploratory in nature, quantitative empirical methods could not yield satisfactory results. Accordingly, the content analysis was considered the most favourable methodological approach in understanding this complex field of research. Structured interviews were used as the main data collection technique during the formative research phase.

\section{Sample}

Selection of the potential interviewees was based primarily on their expertise and experience. Hence, the selection process (Mencinger, Kovač, Jukić and Vintar, 2017; Yin, 2017) itself was predominantly focused on: (1) covering the most relevant public policies for the operation of the Slovenian public administration and beyond (using the classification of PPPPs, defined by the Ministry of Finance), (2) long-term professional experience in developing, enforcing and implementing changes in public policies. Good knowledge of structural, organisational and contextual characteristics of public policy-making process 
in Slovenia by the selected interviewees was supposed to ensure credibility and validity of their views, and recommendations as well as to facilitate constructive participation in the research. In order to obtain the dependable results, the participants had to meet very high professional standards. A non-random stratified sampling approach was used to ensure a representative sample of experts that satisfy the required conditions. The final sample size comprised 22 prominent experts from cross-sectional areas strongly related to public policy-making concept, which have already been engaged in the similar undertakings over the past years. 22 interviewees were chosen from 15 key areas (spatial planning policy, labour and social policy, science and research, traffic policy, migration and asylum policy, budget policy, environmental protection, consumer protection, administrative law and policy, education (primary, tertiary), tax policy, local self-government, health policy, digital policy, cultural policy). Participating expert were typically senior officials affiliated with different institutions: most of them from ministries (15), non-governmental organization (3), inspectorate (2), institutes (1) and agency (1). Most of the interviewees were directors (of directorates, agencies, and institutes), state secretaries, and former ministries. The number of potential participants has not been previously specified. Quotas of experts in each area, totalling to 22 , were determined after reaching saturation point. The experts involved in the interviews are currently occupying the top positions on different levels of the administrative-political system. The participants were aged between 39 to 70 years, whereas the ratio between men and women was 12:10 (12 men $(55 \%)$ and 10 women $(45 \%))$.

\section{Data Collection}

Before the actual start of the interviewing process, pilot interviews were carried out, including certain number of experts from designated areas. The final set of questions was revised in line with their comments and suggestions, which helped to resolve some conceptual weaknesses and ambiguities. Interviews were conducted in the period from February to September 2017. The response rate was about $70 \%$, namely out of about 35 invited experts 22 responded to the invitation and ultimately participated in the interviews. The interviews, which lasted approximately 90 to 120 minutes, were conducted by the authors in person at the official premises of the interviewees. All participants were explained the purpose and objectives of the study to clarify the last details and potential uncertainties pertaining to their assignments. All participants in the interviews gave informed consent and were provided anonymity and assured confidentiality of the information obtained. Given the active role of the participating experts in the interviewing process, special authorization of their responses was not required.

The role of the participating experts within the proposed interviewing process was twofold. First, they had to participate in the analysis of the nature, role and significance of the selected factors for the successful implementation of public policies in Slovenia. Second, drawing from their own experience and knowledge of the administrative-political system in Slovenia they had to provide their vision of the interdependence of factors and their impact (rank by relevance) on the performance of public policies. The aim was to analyse 
and explore how changes in those critical factors facilitate or inhibit the policy process in all of its stages (i.e. agenda-setting, ex-ante evaluation, policy formulation, decisionmaking, policy implementation, and ex-post evaluation). Unresolved issues and existing dilemmas regarding the interviewees' responses were further analytically discussed within the authors' group in the iterative manner.

The interviews consisted of seven compound sections of in-depth questions. The first section contained general information and explored which instruments for designing public policies are being typically used in the Slovenian public administration. The remaining sections of questions were used for the analysis of six interrelated factors (strategic, institutional, normative, economic/financial, methodological/procedural, organisational/human resources/ICT support) in terms of their impact on the decision-making process in the shaping of PPPPs in Slovenia. Questions in the interviews included several different formats, namely: close-ended questions with numerical estimates, and open-ended questions. Responses of the interviewees were voice-recorded, the answers were later converted into transcripts and data tables, and finally the transcripts were documented and archived. The data collected allow the execution of qualitative as well as quantitative analyses.

\section{Data Analysis}

After an extensive review of the literature and investigation of primary and secondary sources containing problem-related content, the empirical part of the research was carried out. In this way, primary quantitative empirical analysis (Mencinger et al., 2017) has been extensively upgraded with new approaches. The data obtained through the empirical qualitative research, have been analysed in accordance with the guidelines proposed by the content analysis methodological framework. Analysis of the data obtained and their interpretations was carried out using the qualitative analysis software - Atlas.ti, which is frequently used in academia, especially for social science research. It is a powerful tool, which can be applied for the analysis of large bodies of textual, graphical, audio and video data (Atlas.ti, 2018). Implementation of the content analysis using Atlas.ti is based on the codifying process of the key concepts of each dimension explored within the textual transcripts. The coding categories were derived from the preliminary theoretical research and directly from the interview transcripts (Hsieh and Shannon, 2005). The basic idea behind the codifying process is to test arguments and assertions of the interviewees by finding the affirmative material quotations and/or references in their responses (interview transcripts). In order to increase the objectivity and credibility of the findings obtained, the final content analysis of the interview transcripts was carried out independently by several coders (authors), whereas all identified inconsistencies were re-evaluated by the coders in a collaborative manner (Iacovino, Barsanti and Cinquini, 2017).

The application of the proposed research design, sampling and the respective data collection technique have been instrumental for the overall data analysis. The latter provided a functional platform for the synthesis and interpretation of data obtained, and ultimately facilitated the development of comprehensive and evidence-based conclusions. 


\section{Results}

One of the main questions discussed in (Mencinger et al., 2017) was to determine which factors have a significant impact on the decision-making process in shaping of PPPPs in Slovenian public administration. Six factors were analysed and their importance in shaping of PPPPs was evaluated from 0 - not important at all, to 4 - very important/crucial. The Table 2 summarises the top box score (i.e. the percentage of the interviewees who evaluated a factor with 4) and the top-two box score (evaluated with 3 or 4 ).

Table 2: Top box and top two-box scores with ranks for the relevance of six analysed factors

\begin{tabular}{|l|c|c|c|c|}
\hline Factor & Top box score & Rank & Top two-box score & Rank \\
\hline Strategic & 0.70 & 1 & 0.80 & 2 \\
\hline Institutional & 0.29 & 4 & 0.67 & 6 \\
\hline Normative & 0.35 & 3 & 0.9 & 1 \\
\hline Methodological/procedural & 0.25 & 6 & 0.7 & 5 \\
\hline Economic/financial & 0.29 & 4 & 0.71 & 4 \\
\hline $\begin{array}{l}\text { Organisational/human } \\
\text { resources/ICT support }\end{array}$ & 0.37 & 2 & 0.79 & 3 \\
\hline
\end{tabular}

Source: authors based on own analysis

Among six interrelated factors, the interviewees ranked them in terms of their importance based on top box score in the following order: strategic, organisational/human resources/ICT support, normative, institutional, economic/financial, and methodological/procedural. A slightly different ranking appears if we analyse top two-box scores (Table 2). Hence, according to 22 prominent and top ranked experts participating in the study, the strategic factors were outlined as the most crucial factors by far in Slovenia (Mencinger et al., 2017).

Based on the initial literature review (Graham et al., 2003; Hicklin and Godwin, 2009; Howlett and Ramesh, 2003; Kerwin and Furlong, 2018; Nowlin, 2011) and preliminary research findings concerning the public policy-making context in Slovenia, we focused on the formation of seven hypotheses that were tested in this qualitative study. Outlined hypothesis $(\mathrm{H})$ cover the most relevant factors defined above:

H1: EU stakeholders have a positive impact on implementation and evaluation of public policies;

$\mathrm{H} 2$ : Evaluation of public policies is not systematically performed;

H3: Changes of government represent discontinuity of carrying out public policies;

H4: Collaboration between various departments is insufficient;

H5: Consultation with public is not carried out systematically;

H6: Slovenia insufficiently enforces its national specifics within the EU and international documents;

H7: In the absence of an official strategy, decision-making is moved from a political to an administrative level. 
The hypotheses verified in Atlas.ti are represented with the networks in the following subsections. In each network, the central node corresponds to the tested hypothesis, and its neighbouring nodes correspond to Atlas.ti "codes", i.e. a group of substantially matching quotations from the interviews. In this section, we discuss each hypothesis through its network representation from Atlas.ti.

\section{Verification of the hypotheses}

The networks in figures presented below substantially summarise the claims that confirm the abovementioned hypothesis. The claims are more extensively analysed and elaborated in the continuation, whereas other circumstances, contexts and opinions that could influence the argumentations expressed are outlined as well.

Figure 1: Network representation of hypothesis »EU stakeholders have a positive impact on implementation and evaluation of public policies«

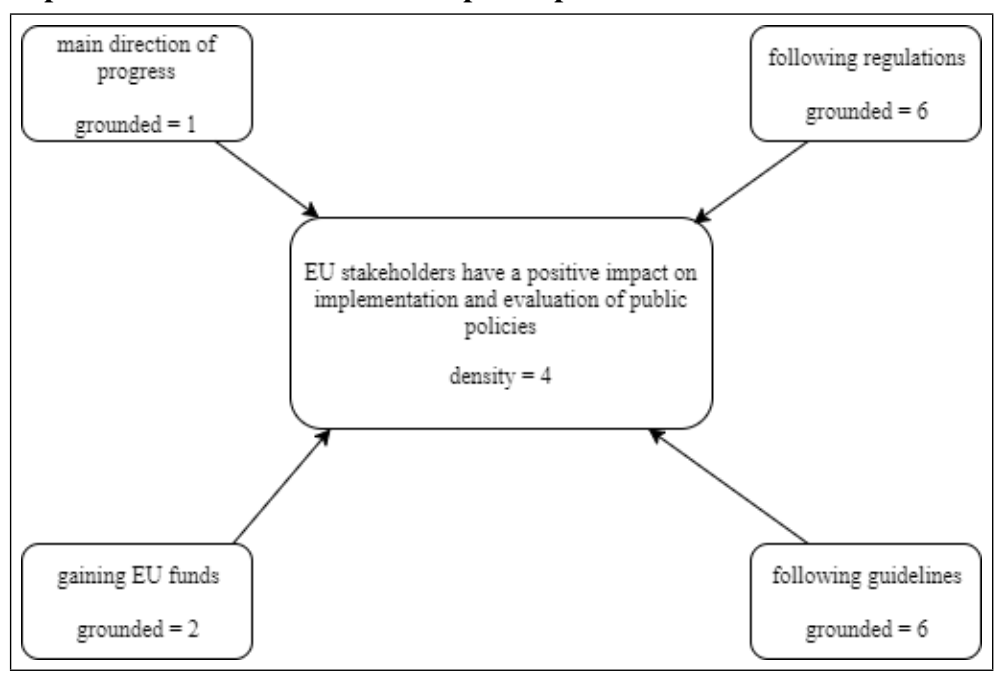

Source: authors based on conducted interviews

The central node in Figure 1 has four neighbouring nodes (Atlas.ti codes). The number of nodes is designated as "density" in graphic representations. It means that we identified four main grounds that support H1. The frequencies "grounded" indicate the explanation power of each code. The Figure 1 shows that the codes "following regulations" and "following guidelines" are supported by six quotations, "gaining EU funds" by two quotations, and "main direction of progress" by one quotation. In other words, the impact of EU stakeholder on implementation and evaluation of PPPPs is mostly reflected in terms of following regulations and guidelines. To illustrate this finding, we selected two direct quotations from the interviews. "EU policies are the main directions of development. Adopting legislation at EU level imposes a high degree of unification of different policies." and "In the field of labour, family and social affairs, the EU rules are fully implemented in practice." 
These findings were confirmed by the quantitative analysis as well (see Mencinger et al., 2017). Most of the interviewees (65\%) agreed that PPPPs are strongly related to EU or other international organisations (OECD, WHO). The PPPPs are either a part of the implementation of European and other international regulations $(27.5 \%)$, or a part of the European or international development policies $(37.5 \%)$, where the recommendations are (at least formally) non-binding. Similarly, $38 \%$ of the interviewees find EU regulations as one of the key instruments in designing (planning, execution, evaluation) of public policies.

Figure 2: Network representation of hypothesis »Evaluation of public policies in not systematically performed $\ll$

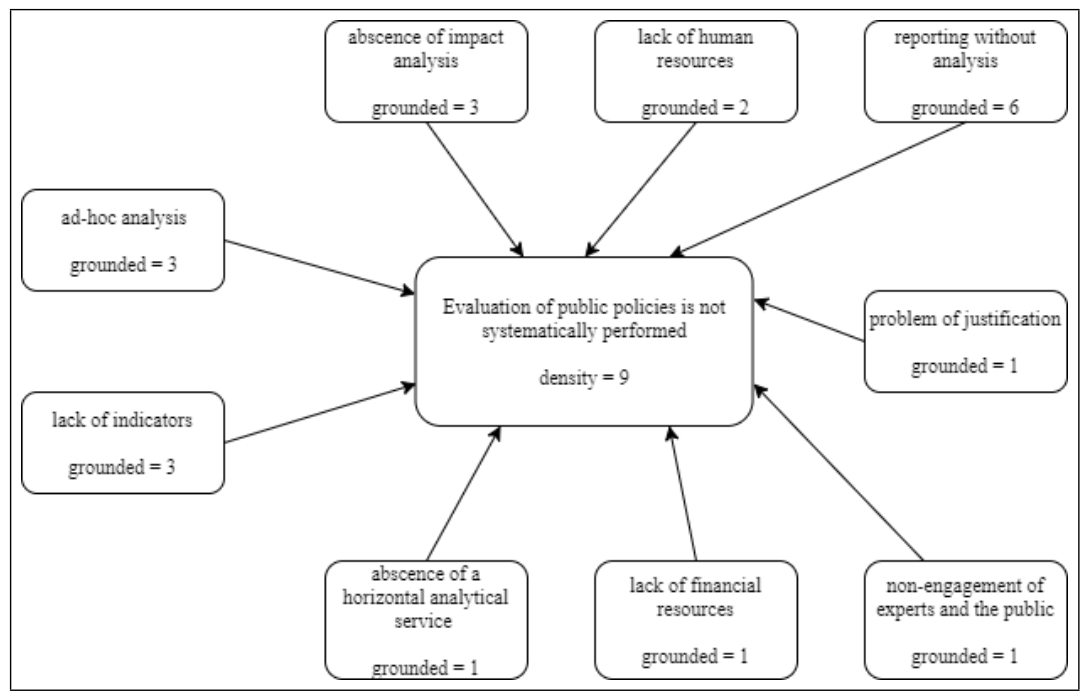

Source: authors based on conducted interviews

Figure 2 shows that evaluation of public policies in Slovenia should be more systematically performed. There are nine codes supporting this claim. The code that is grounded by most quotations (six) is "reporting without analysis" which clearly indicates the absence of clearly defined and practical evaluation process. An illustrative example of such quotation is: "We report a lot to the EU, but no real evaluation is carried out."

Other codes, like "absence of impact analysis" or "ad-hoc analyses" suggest that "some kind of evaluation" is carried out, but it should be more thorough and methodical. Each of them is supported by three quotations, for instance: "We did not even ask officials or the public. No one asked what the effects of the implementation of public policy are." In several situations, the officials would like to evaluate policies, but there exist certain obstacles, in terms of lack of indicators (three supporting quotations), lack of human (two quotations) of financial resources (one quotation). The quotation: "We do not have enough employees. When one job is done, the employee is assigned to a completely different project." illustrates such situation. 
The findings of qualitative analysis are consistent with the results of the quantitative analysis. Namely, $43 \%$ of the interviewees think that evaluations are systematically performed in implementation of PPPPs, while the opinion of $38 \%$ of the interviewees is neutral.

Figure 3: Network representation of hypothesis »Changes of government represent discontinuity of carrying out public policies«

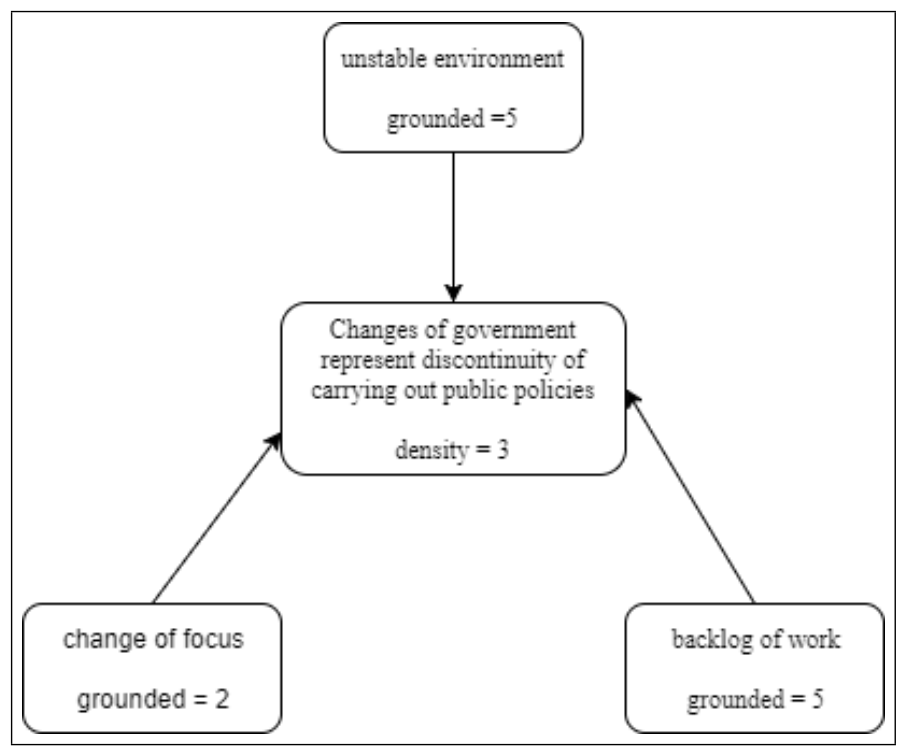

Source: authors based on conducted interviews

In the last decade, there were four parliamentary elections in Slovenia. The changes of government were therefore frequent, which resulted (according to network in Figure 3) in "unstable environment" and "backlog of work". These two codes are supported by five quotations, for instance: "We had several organisational changes due to change of government in the last five, six years". Another problem when government changes is reflected in the quotation: "Change in government announces a change in tax legislation (the impact of politics on the structure of the institution itself)." This is an example of change of focus, another code from the network (supported by two quotations).

The findings of qualitative analysis are in accordance with the results of the quantitative analysis. Namely, $70 \%$ of the interviewees report that changes of government - especially from the left- to the right-wing one or vice versa - have a significant impact on the implementation of PPPPs in Slovenia. This percentage would probably be even higher if all policies followed a strategic plan. One of the interviewees graphically described: "We have no strategy, therefore the change of government has no influence." Although this quotation seems to contradict the hypothesis, the actual situation might be opposite: the presence of strategy forces new governments to continue with the execution of the existing policies. 
Figure 4: Network representation of hypothesis »Collaboration between various departments in insufficient «

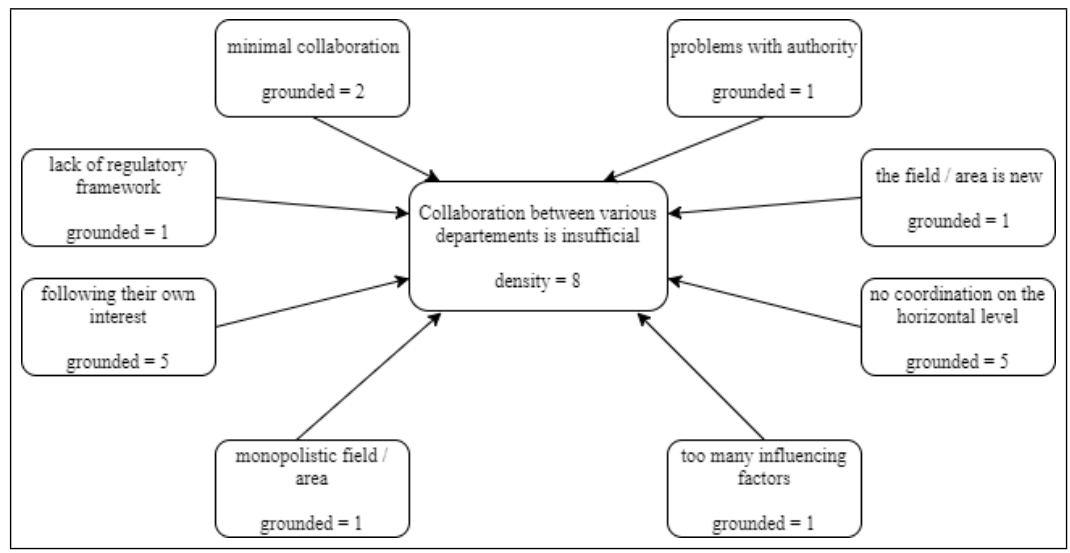

Source: authors based on conducted interviews

Most interviewees (55\%) believe that the current institutional organisation allows adequate implementation of public policies. However, they are mostly sceptical about the quality of collaborations between various departments. As shown in Figure 4, there exist many grounds why such collaboration is insufficient. Although our study pointed out eight grounds (eight codes) two of them play a significant role (grounded by five quotations). The codes grounded by five quotations are "no coordination on the horizontal level" and "following their own interests". For instance: "There is no proper regulatory framework to change a number of laws/regulations - there is a lack of a horizontal dimension."

The other codes are supported by fewer citations - the reasons why collaboration between various departments is not sufficient, include: lack of regulatory framework, monopolistic area, problems with authority, and too many other factors that have influence on such collaboration. Some interviewees indicated minimal level of collaboration within the same department: "There are no steps forward in interdepartmental cooperation, despite the fact that science and higher education belong to the same ministry."

We can deduce from Figure 5 that six quotations confirm the claim that "consultation with public is not carried out systematically". The strongest reason is in impact of other stakeholders (grounded by five quotations) and existing politics (three quotations). These eight quotations are related to opinion that public has weak power (two quotations). Additional reasons might be related to poor informing (three quotations) or inconsistency with political goals (two quotations). For illustration, a quotation from the interview expressed: "Non-governmental organisations often take over the role of public. Their influence is therefore stronger."

The consultations with various stakeholders concerning the development of public policies was also a part of quantitative analysis (Mencinger et al., 2017). The interviewees ranked four stakeholders ("general" public, economy, professional public (e.g. academic sphere), and non-governmental organisations) in terms of their contribution to better preparation, 
design and development of policies. The "general" public was ranked on average third place (average rank was 3.0) of importance with 37\% of the interviewees found its contribution least significant. Contrary, the average rank for "professional" public was 1.7 with almost half of the interviewees (48\%) that found its contribution the most significant. The Figure 5 is therefore consistent with the quantitative analysis when the word "public" refers to "general public".

Figure 5: Network representation of hypothesis »Consultation with public is not carried out systematically «

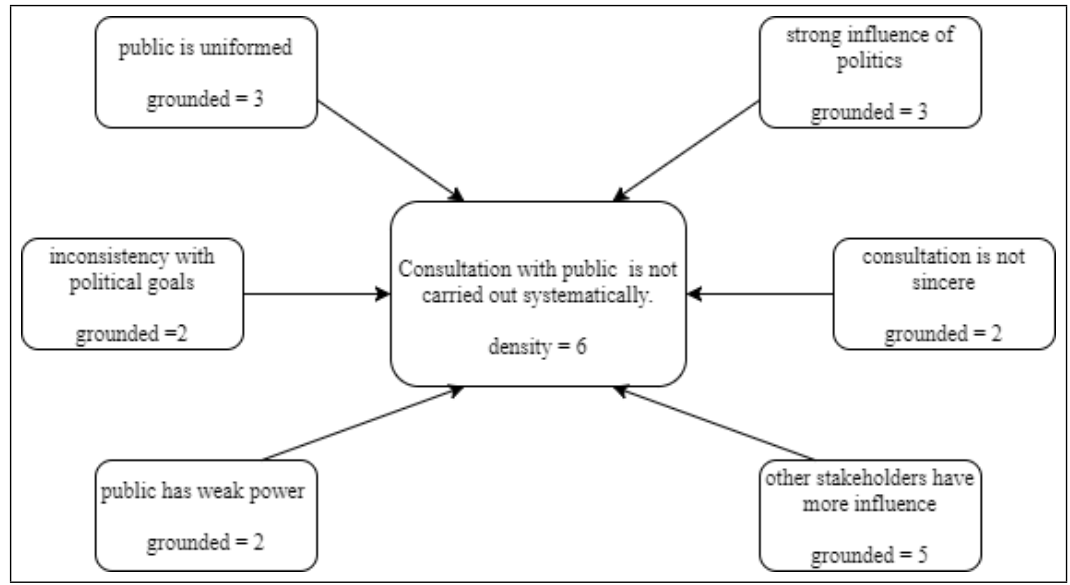

Source: authors based on conducted interviews

Figure 6: Network representation of hypothesis »Slovenia insufficiently enforces its national specifics within the $\mathbf{E U}$ and international documents«

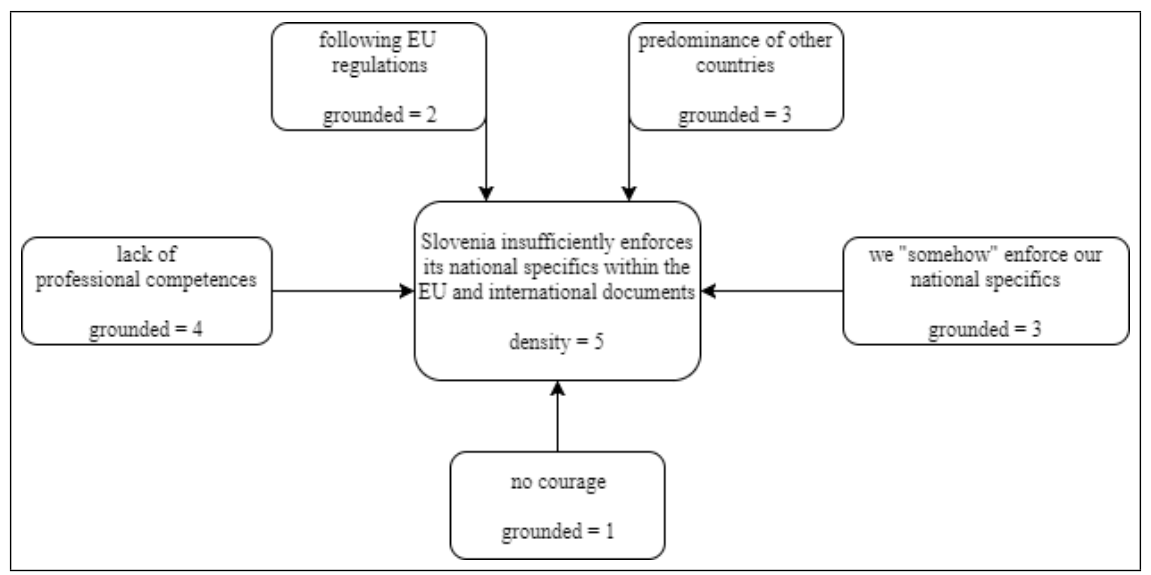

Source: authors based on conducted interviews 
From the Figure 6 we can conclude that five grounds confirm hypothesis 6 . The lack of professional competences plays the most important role since it is supported by four quotations. For illustration, we provide a quote related to the scientific research policy: "We are relatively weak at managing public policies in accordance with our national specifics, as there is no horizontal integration." Predominance of other countries is also an important reason why Slovenia insufficiently enforces its national specifics. It is supported by three quotations, for instance: "Austria maintains internal border control (among five countries) and insists that it is the last state to defend the Schengen area. Slovenia lost this border dispute due to political interest of other countries."

The findings of qualitative analysis are partially in accordance with the results of the quantitative analysis. Namely, $44 \%$ of the interviewees think that the implementation of PPPPs in Slovenia follows the national interest, while 28\% think the opposite (28\% are neutral). An example of such policy (neutral opinion) is the cultural policy, which is autonomous with respect to the EU.

Figure 7: Network representation of hypothesis »In the absence of an official strategy, decisionmaking is moved from a political to an administrative level«

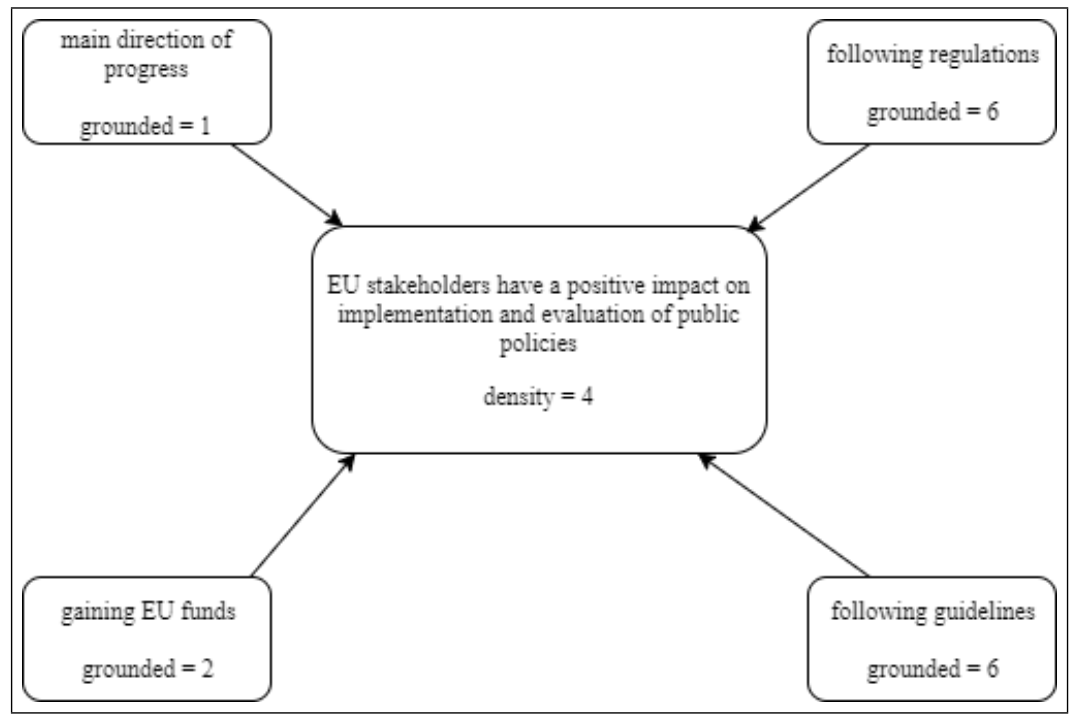

Source: authors based on conducted interviews

From the Figure 7 we can identify six situations where in the absence of an official strategy, decisions are moved from the political to the administrative level. Nevertheless, such decisions need a political support from the current minister or the whole government (code with 12 quotations). The role of professional service is also important (5 quotations) since such services sometimes substitute inactive political decision makers (2 quotations). These views and opinions illustrate an important role of the public administration (bureaucracy) in the process of policy-making. Although public administration should be politically 
independent from the politics in the policy implementation, the strong connections, interdependences and even conflicts still exist. As one of our interviewees illustrated: "The Directorate can prepare a document, but the minister must confirm it, and his/her support needs to be obtained. In the end, the minister is always the one who says yes or no".

Hypothesis 7 has not been evaluated previously within quantitative analysis since there was no direct question in the interview that could verify it. In the beginning of this section we mentioned that $\mathrm{H} 7$ was set as a hypothesis, which covers the impacts of all six factors we analyse in the paper. The quotations confirming $\mathrm{H} 7$ were therefore found and confirmed in various parts of the interviews.

\section{Discussion}

Public policies have a major impact on the society, regardless of being led efficiently or even more significantly, when lacking performance. Hence, its holders, both on the political and administrative levels, must follow all fundamental public policy-making principles reflected in formal public policy cycles in order to provide sound governance in national and supra-national relevant common issues (Ongaro and van Thiel, 2018). As proven by numerous theoretical sources and international research (for instance, see Howlett et al., 2015; Raadschelders, 2011; Zito, 2015, etc.), particularly the highly complex and rapidly changing environment in public affairs challenge us all to search for relevant factors in successful implementation and execution of public policies. In the context of certain types of countries, such as Slovenia, that faces various public issues and concerns, among others post-socialist legacy and transitional burdens, and yet unformed and unstable governance mechanisms (see Kovač and Bileišis, 2017; Vintar et al., 2018), identification of critical factors is even more important.

Our empirical study provided us with a comprehensive textual data set, which was extensively analysed in this paper. Although our sample covered the most relevant public policies in Slovenia and prominent experts from practice, there are some issues that need to be further discussed. They are mostly related to the topic of "public policy-making cycle". Our presumption that all public policy cycles have to follow at least some basic public policy-making standards to a certain extent, are an inevitable precondition to develop successful PPPPs (Howlett and Ramesh, 2003; Vintar et al., 2018). Namely, if any respective phase or fundamental good governance principle is missing, one cannot argue that public governance in certain community delivers effective public policies. In Slovenian and similar countries' context, it is still very hard to find relevant experts on this topic since this area is underdeveloped and scattered over specific policy areas. Moreover, our participating experts cover different public policies and have not been involved in all stages of public policy-making process. Their perception/understanding of the questions could be therefore biased towards the policy they cover and the phases in implementation cycle with which they have most experiences. Hopefully, our representative sample overcame potential bias of their perception, since this gap has been tried to be mitigated by a thorough methodological verification. 
Regarding the basic two research questions, put forward initially (analysis of the role, significance and interdependence of the selected factors in delivering PPPPs), we can firmly establish that there are several various groups of factors, directly influencing the successfulness of public policies' design and implementations, in Slovenia at least. Namely, based on correlating sources and methods, it is obvious that strategic dimension is the most critical, while other pre-determined factors play rather a complementary role. In other words: if country has no clear strategy and well-defined long-term goals (see in detail particularly subsections on verification of hypotheses 2, 6 and 7), it does not matter how efficient resources it has. Moreover, one cannot implement all public policy cycle phases and then improve PPPPs in theoretical sense, (see, for instance DiMaggio and Powell, 2000; Keping, 2018; Toma et al., 2005), when the main strategic goals are not set. All things considered, the basic question arises: how to conduct an evaluation without strategic framework? In sum, we can answer, generally as well as particularly for Slovenia, that a feed-back loop is crucial, and a full public policy cycle with all steps (even though some phases are formally or partially in place) is necessary to establish the efficient public policy-making practice. This actually confirms that ultimately only an adequate combination of strategic, institutional, normative, economic/financial, methodological/procedural, and organisational/human resources/ICT support factors can provide a comprehensive success in the field of public policies; notwithstanding that the strategic factors were exposed as the most critical of all.

Slovenia is an example of bad practice regarding the public policy cycle and all required phases (formal and material), since evaluation, as one of the key stages of public policymaking cycle (Howlett and Ramesh, 2003), in many cases does not exist in its true or strategic sense or is only formal(istic). And when there is some, at least partial evaluation, it is even more rarely used as a ground for further evidence-based decisions and policymaking (as characteristic for a broader region also, (see Kovač and Bileišis, 2017)). These findings were revealed from the verification of the second hypothesis (see related Figure 2 with even nine grounded nodes, which is the highest value of all hypotheses). Hereby, an issue of relation between politicians and public administration is also evident (Nowlin, 2011), since it is not an exceptional case that "public policies" (and laws) are prepared ad hoc and based on daily political interests and media pressures. In future, regulatory impact analysis with public engagement should be carried out more strictly and without exception. Moreover, we believe that there is a need to identify the general catalogue of effective public policies' indicators that would lead policy makers to check whether they have respected all relevant steps, circumstances and factors (as performed in the case of some individual sectors like taxation or for more measurable horizontal policies, like e-government).

The execution of the full public policy cycle is especially relevant when discussing cross-sectoral public policies. The results for Slovenia reveal primarily a lack of interdepartmental cooperation (e.g. migrations in the recent period should not be only under the jurisdiction of the Ministry of the interior, but also Ministry of foreign affairs and Ministry of education, science and sports (see Vintar et al., 2018)). The latter is rather a consequence and not a cause, which arises from rather poor design and implementation of respective 
policies that originate from weak strategic framework. This is confirmed by verification of the first hypothesis on the EU influence on national policy-making processes, since it has been proven that EU pressure (in various forms) can partially replace otherwise national strategies. In case where EU policies steer the national ministries, especially through a harmonisation of legislation, we can observe much more successful implementation of policies and ultimate outcomes. However, this claim is true, as long as the national interests coincide with the general orientations of the $\mathrm{EU}$ and are adequately represented at the $\mathrm{EU}$ level. This is certainly not the case for Slovenia, due to its small size, diminutive power and historical reasons, but even more for its lack of competence in the field, general focus and clear top down goals. Moreover, in a rather formal environment characteristical for central Europe, legislation can serve as a strategic platform, as long as it is sufficiently broad and based on general strategic orientation of the country (e.g. case of construction sector and taxation as revealed in this analysis). Therefore, consistent legislation and procedural aspect of law-making might be the first step to build upon strategic public policy-making processes and sound governance in countries such as Slovenia. But in a long run, more interdisciplinary approach to resolving political-administrative dilemmas is required (Ongaro and van Thiel, 2018; Raadschelders, 2011).

Some of the interviewees could have potentially influenced the relevance of their answers but the main results regarding the identification and categorisation of factors would not differ as confirmed by other analysis, especially the sources on environmental complexity in public affairs (see Mencinger et al., 2017; Mintrom and Luetjens, 2017; Zito, 2015). Namely, the interviewing process in our research was long and complex; it was therefore hard to expect that the interviewees will provide perfectly consistent and hence, objective and insightful answers on all questions. Sometimes their answers on Likert scale (expressed as the level of agreement) were not in line with their explanations that followed. Nevertheless, we believe that their explanations provided us with relevant information, since it is usually very hard to decide which level on opinion scale to choose. Such situation is for instance reflected through the hypothesis 6 (Slovenia insufficiently enforces its national specifics within the EU and international documents), especially through code "we somehow enforce our national specifics". At first sight, this code seems to contradict the hypothesis, but the word "somehow" implies that the enforcement should be more extensive and frequent.

To wrap it up, in our empirical study we analysed the influence of six factors for successful implementation of public policies, that is strategic, institutional, normative, methodological/procedural, economic/financial, and organisational/human resources/ICT support factors. Although we identified and selected these factors in various theories, our choice can be in some way considered as arbitrary, but we allowed the interviewees to add or redefine them if necessary, which was not the case. Therefore, we consider these factors as sufficiently objective and legitimate to make some sound conclusions upon them. Based on these six factors, we formed several hypotheses. However, it is sometimes hard to link a hypothesis to a factor or its prevailing character, since some of them are related to multiple hypotheses. For instance, in our paper the first hypothesis "EU stakeholders have a positive impact on implementation and evaluation of public policies" is classified 
as a hypothesis related to the predominantly institutional factors, although many of the supporting codes and quotation are related to the strategic factors.

Most of the empirical findings indicate that implementation of public policies faces several challenges. Even a positive impact of EU stakeholders signalises a problem: strategic documents are written primarily on the requirements from European Commission, not from our own needs and strategic long-term goals. This is related to insufficient enforcement of Slovenian national specifics within the EU and international documents. Our approach of shaping public policies is "ad-hoc" mainly due to the lack of knowledge, experience, courage and power. Nobody has a comprehensive overview of actions in the past, the current situation, the experience from other countries etc., so it seems like we improvise most of the time. The other reason apart from "improvising" in design and implementation of policies is also the lack of resources and knowledge (financial, human, etc.). The consequences of such improvisation are: search for public policy shortcuts (which often turn out to be aberrations), temporary and partial public policy solutions, public policies without clear arguments and national consensus, public dissatisfaction, deficiently shaped and targeted policies and consequently unsatisfactory outcomes of policies, etc. The participants pointed out that one of the greatest weaknesses in most of the institutions responsible for design and implementation of public policies is the absence of a specialized unit, called "policy unit". The role of such unit would be monitoring and care for the design and implementation of PPPPs in the long run. This demanding task is therefore again "improvised", left to "ad-hoc" groups constituted upon the political needs of the ruling coalition.

The importance of the normative factors is often over-emphasised due to existing hyperregulated normative environment in Slovenia. The preparation of the new legislation is often the only measure that our governments are willing to take. The legislation changes are so frequent that the monitoring of their effects and implications is very difficult. Evaluations of expected effects/outcomes of public policies are therefore rarely carried out. The other big problem deduced from our study is related to constant changes of governments and weak coalitions. One of our participants graphically illustrated that each government starts "with the birth of Christ", that is from nothing. The experience and the gained knowledge from predecessors are in most cases irrelevant. That increases the implementation periods, overall costs and decreases the effects. Due to our electoral system after each election, we get a coalition government. As a result, policies are often not based on comprehensive expert analyses and projections, but on ideological orientations, bargaining and coalition contracts/agreements. Considering their internal inequalities, the weak coalition governments are not able to form a unified vision, or define national long-term goals, consistent foreign policy approach, etc. Due to the frequent changes of governments and ministers in individual sectors, the transfer of powers from a political level to the administrative (bureaucracy) level is a rather common phenomenon, which can have detrimental effects on the shaping of public policies. The latter phenomenon and the reasons for it, as well as possible consequences, have already been mentioned and elaborated in greater detail in the preceding sections of this paper. 
Some other problems that come out from our study are related to the public. There is often insufficient interest of the professional public in the process of public debate. On the other hand, communication between the public authorities and the public is often scarce and inadequate, which leads to unrealistic expectations from certain policies. Consequently, the effect of the policy is lower than it could be, which is reflected in dissatisfaction of the general public, which additionally undermines the credibility of all other national policies as well as any potential good national projects that are planned or are being implemented. Public support for PPPPs is regarded as almost not relevant, despite the fact that expert and general stakeholders' engagement has proven to be decisive in the public policy-making cycle, especially in terms of more rational, argumented and evidence-based policy-making processes. In 2016, for example, in $32 \%$ of the cases in legislative procedure, no public consultation was carried out on grounds of urgency by order of the minister, while, on the other hand, the ministries received very few replies, comments or amendments on average only 4 per one legal proposal (as established by Vintar et al., 2018). Here, the matter of political culture and democratic traditions are in question, however, authorities are the first to be called upon more proactive, open-minded and all-inclusive approach.

Considering the general and methodological limitations of the presented study, some issues have to be pointed out. Since our key factors have been arbitrarily selected in advance and pre-determined in a theory-based manner, the results and conclusions derived from the interviews can be interpreted and argued to some extent in different ways. We verified the relevance of the key factors through interviews, which did not allow us to consider all potential restrictions, i.e. the conditions that occur in the real environment. Accordingly, we believe that further research should be focused primarily on the deepening of the knowledge and understanding in the field of public policy-making including the identification and analysis of the key factors in the real environment, and their verification in factual situations concerning the process of design and implementation of public policies. The other limitation is related to the representation of the results. When striving to represent empirical findings in a clear and reasonable way, we faced certain methodological dilemmas. For instance, we grouped quotations from the interviews to "codes", where each code corresponded to a set of substantially similar and analogous quotations. Determining similarities and analogousness between two quotations as well as the naming of the codes may have been, however, subjectively biased. Our decisions were based on the intention to represent the expressed opinions of the interviewees and deriving research results in the most transparent and understandable way.

Concerning the delicate and intriguing relationship between politics (government and appointed ministers) and bureaucracy (high-ranked and senior officials at ministries), it is evident that competences and accountability of the involved actors should be scrutinised, re-defined, and elaborated more extensively (cf. Farazmand, 1997; Hicklin and Godwin, 2009; Nowlin, 2011; Rahman, 2015), etc.). Nevertheless, we believe that presented analysis provides some valuable insights and an applicable platform that could be beneficial to comparative countries facing similar challenges and can thus serve to promote research and convey concrete improvements in the field. 
Finally, we wish to propose some other recommendations. Based on the content analysis and with regard to outlined hypotheses, it is very clear that a holistic PPPPs model should be developed in Slovenia, incorporating (i) all public policy phases, (ii) various factors of successful PPPPs design and implementation, and (iii) specific indicators, contributing to effective public policies, good governance and better normative regulation. As one of the initial steps, we recommend the establishment of sectoral and above all, central policy unit, under government auspices, which should guarantee that all public policies have undergone the formal public policy cycle and are compliant with the aforementioned model, before their final national implementation. This central policy unit could serve as a motor of public policy development, and provide supervision and evaluation throughout the policy design and implementation processes. The central policy unit should also be responsible for and able to articulate and promote national interests in negotiations with the EU. The strategic development without a doubt significantly contributes to effective PPPPs implementation, hence more attention should be dedicated to the design of midterm strategies, while respecting a cascade principle with an umbrella strategy on the Slovenian national level and compatible cross-sectoral and sector specific policies and programmes on lower levels. Public consultation and deliberation procedures should be enhanced not only for the sake of formal compliance with the EU or OECD guidelines, but to prepare better public policies and increase trust into democratic authorities, public administration, and their efficiency.

\section{Conclusion}

Public policies and their systemic design and implementation require a mixture of political and professional approach. Otherwise, public policies are incapable of initiating and promoting socio-political development at the national level and are completely pointless from this point of view. Therefore, any given country should introduce a comprehensive and systemic attitude towards PPPPs design and overwhelmingly care their implementation. If there are deviations between set public policies, their purpose and objective circumstances, corrective measures should be taken - not necessarily in the form of new or amended normative regulations. This research confirms that PPPPs design and implementation are effective as far as it is carried throughout the entire public policy cycle coherently. When certain steps are underrated, the effects are not optimal or could be even counterproductive. When developing a holistic model of PPPPs, all of these phases should be part of the overall puzzle as theoretically grounded by different public policy and governance theories. Moreover, the identified factors of success (on a national scale), primarily strategic and institutional ones, need to be incorporated. Based on the empirical research results, special attention in the future will be required concerning the professionalism of PPPPs design. These future efforts should among other things, especially try to mitigate the influence of daily political developments and ad hoc media produced topics on the overall public policymaking sphere in Slovenia. Particularly in terms of these research findings that reveal the differences between the declared standards and the practice, it is obvious that knowledge should be more extensively transferred from theory to practice. Presented content analysis as a methodological ground provides hereby relatively objective basis to establish the state 
of the art on one hand, and a desired situation, on the other. Thus, a tangible progress can be made even in (post)transitional circumstances and in the situation of limited resources and competences. To conclude, in the future more attention should be focused on raising the awareness regarding the importance of public policy cycle and key factors determining polices' success, in public governance research and practice alike.

\section{Acknowledgement}

This article is a result of the project Development of the model for monitoring and evaluation of development programmes and projects in public sector, No J5-7557. The authors acknowledge the financial support of the Slovenian Research Agency. More information at http://atena-kronos.si/en/.

\section{References}

Al-Mamari, Q., Corbitt, B. and Oyaro Gekara, V. (2013). E-government adoption in Oman: Motivating factors from a government perspective. Transforming Government: People, Process and Policy, 7(2), 199-224.

Atlas.ti. (2018). What is ATLAS.ti? Retrieved February 14, 2018, from https://atlasti.com/ product/what-is-atlas-ti/.

Bache, I. and Flinders, M. (eds.) (2004). Multi-level Governance. Oxford: University of Oxford.

Bamberger, P. A., Meshoulam, I. and Biron, M. (2014). Human resource strategy: Formulation, implementation, and impact. New York: Routledge.

Bennett, C. J. and Howlett, M. (1992). The lessons of learning: Reconciling theories of policy learning and policy change. Policy Sciences, 25(3), 275-294.

Bressers, H. Th. A. and O'Toole, L. J. Jr. (2005). Instrument selection and implementation in a networked context. In Designing government: From instruments to governance. Pearl Eliades, Margaret M. Hill, and Michel Howlett (eds.). pp. 132-153: London: Montreal \& Kingston.

Cairney, P. (2013). Standing on the shoulders of giants: How do we combine the insights of multiple theories in public policy studies? Policy Studies Journal, 41(1), 1-21.

Council of Europe. (2018, July 8). Strategy for innovation and good governance at loval level. Retrieved January 5, 2018, from https://www.osce.org/eea/86380?download=true.

DiMaggio, P. J. and Powell, W. W. (2000). The iron cage revisited institutional isomorphism and collective rationality in organizational fields. In Economics meets sociology in strategic management (pp. 143-166). Emerald Group Publishing Limited.

Downs, A. (1957). An Economic Theory of Democracy. New York: Harper \& Bross. EC. (2015). Communication from the Commission to the European Parliament, the Council, the European Economic and Social Committee and the Committee of regions. Better regulation for better results - An EU agenda. Retrieved February 4, 2018, from https://eurlex.europa.eu/legal-content/EN/TXT/PDF/?uri=CELEX:52015DC0215\&from=EN. European Parliament and the Council. (2016). Predlog uredbe Evropskega parlamenta in Sveta o odprti, učinkoviti in neodvisni evropski upravi. Retrieved May 22, 2018, from 
http://www.europarl.europa.eu/meetdocs/2014_2019/plmrep/COMMITTEES/JURI/DV/ 2016/04-20/1090614_CLEAN_SL.pdf.

European Union. (2018). Regulations, Directives and other acts. Retrieved March 4, 2018, from https://europa.eu/european-union/eu-law/legal-acts_en.

Farazmand, A. (1997). Bureaucrats and Politicians in comparative Perspective in Ali Farazmand (ed.). In Modern Systems of Government (pp. ix-xvii). London: SAGE Publications, Inc.

Gichoya, D. (2005). Factors affecting the successful implementation of ICT projects in government. The Electronic Journal of E-Government, 3(4), 175-184.

Graham, J., Plumptre, T. W. and Amos, B. (2003). Principles for good governance in the 21 st century. Ottawa: Institute on governance.

Hicklin, A. and Godwin, E. (2009). Agents of change: The role of public managers in public policy. Policy Studies Journal, 37(1), 13-20.

Howlett, M., Mukherjee, I. and Woo, J. J. (2015). From tools to toolkits in policy design studies: The new design orientation towards policy formulation research. Policy and Politics, 43(2), 291-311, https://doi.org/10.1332/147084414X13992869118596.

Howlett, M. and Ramesh, M. (2003). Studying Public Policy: Policy Cycles and Policy Subsystems. Toronto: Oxford University Press.

Hsieh, H.-F. and Shannon, S. E. (2005). Three approaches to qualitative content analysis. Qualitative Health Research, 15(9), 1277-1288, https://doi.org/10.1177/1049732305276687.

Iacovino, N. M., Barsanti, S. and Cinquini, L. (2017). Public Organizations Between Old Public Administration, New Public Management and Public Governance: The Case of the Tuscany Region. Public Organization Review, 17(1), 61-82, https://doi.org/10.1007/s11115-015-0327-x.

IFAC. (2004). Enterprise Governance. Getting the Balance Right. Retrieved May 3, 2018, from http://www.ifac.org/system/files/downloads/Enterprise_Governance.pdf.

Johnston, M. (n.d.). Good Governance: Rule of Law, Transparency, and Accountability. Retrieved February 2, 2018, from http://unpan1.un.org/intradoc/groups/public/documents/ un/unpan010193.pdf.

Keping, Y. (2018). Governance and Good Governance: A New Framework for Political Analysis. Fudan Journal of the Humanities and Social Sciences, 11(1), 1-8, https://doi.org/ 10.1007/s40647-017-0197-4.

Kerwin, C. M. and Furlong, S. R. (2018). Rulemaking: How government agencies write law and make policy (Fifth edition). American University and State University of New York at Oswego. Thousand Oaks, California: CQ Press.

Kooiman, I. (2003). Governing as Governance. London: SAGE Publications, Ltd.

Kotnik, Ž. and Kovač, P. (2018). Development of Public Administration and Governance in Central and Eastern Europe: Content Analysis of The NISPAcee Journal. NISPAcee Journal of Public Administration \& Policy, 11(1), 229-252.

Kovač, P. and Bileišis, M. (Eds.). (2017). Public Administration Reforms in the Eastern European Union MS: Post-Accession Convergences and Divergences. Retrieved March 3, 
2018, from https://www.dlib.si/stream/URN:NBN:SI:DOC-GOZLT0QL/dc9c67f3-b6ef4ddb-8f03-28ef0dd1deb2/PDF.

Kraft, M. E. and Furlong, S. R. (2007). Public policy: Politics, analysis, and alternatives (2nd ed.). Washington, D.C.: CQ Press.

Laforet, S. (2011). A framework of organisational innovation and outcomes in SMEs. International Journal of Entrepreneurial Behavior \& Research, 17(4), 380-408.

Lecerf, M.-A. (2012). Internationalization and innovation: The effects of a strategy mix on the economic performance of French SMEs. International Business Research, 5(6), 2-13. Marquis, C. and Tilcsik, A. (2016). Institutional equivalence: How industry and community peers influence corporate philanthropy. Organization Science, 27(5), 1325-1341.

May, P. J., Workman, S. and Jones, B. D. (2008). Organizing Attention: Responses of the Bureaucracy to Agenda Disruption. Journal of Public Administration Research and Theory, 18(4), 517-41.

Mencinger, J., Kovač, P., Jukić, T. and Vintar, M. (2017). Public Policy Design and Implementation in Slovenia. International Public Administration Review, 15(3-4), 9-38. Meyer, J. W. and Rowan, B. (1977). Institutionalized organizations: Formal structure as myth and ceremony. American Journal of Sociology, 83(2), 340-363.

Minor, M., Bergmann, R. and Görg, S. (2014). Case-based adaptation of workflows. Information Systems, 40, 142-152.

Mintrom, M. and Luetjens, J. (2017). Creating Public Value: Tightening Connections Between Policy Design and Public Management. Policy Studies Journal, 45(1), 170-190. MJU. (2015). Javna uprava 2020. Strategija razvoja javne uprave 2015-2020. Retrieved March 12, 2018, from http://www.mju.gov.si/fileadmin/mju.gov.si/pageuploads/JAVNA_UPRAVA/Kakovost/Strategija_razvoja_SLO_final_web.pdf

North, D. C. (1990). Institutions, Institutional Change and Economic Performance. Cambridge: Cambridge University Press.

Nowlin, M. C. (2011). Theories of the policy process: State of the research and emerging trends. Policy Studies Journal, 39(1), 41-60.

Ongaro, E. and van Thiel, S. (Eds.). (2018). The Palgrave Handbook of Public Administration and Management in Europe. London: Palgrave Macmillan.

Raadschelders, J. C. N. (2011). Public Administration: Interdisciplinary Study of Government. Oxford: Oxford University Press.

Rahman, M. S. (2015). Politics-Bureaucracy Relations, Governance and Development in Bangladesh: The Case of Local Government. Ruprecht-Karls-Universitat Heidelberg, Heidelberg.

Robinson, S. E., Caver, F., Meier, K. J. and O'Toole, L. J. Jr. (2007). Explaining Policy Punctuations: Bureaucratization and Budget Change. American Journal of Political Science, 51(1), 140-50.

Scott, W. R. (1995). Institutions and Organizations. Thousand Oaks, CA: Sage.

Stoker, G. (2006). Public value management: A new narrative for networked governance? The American Review of Public Administration, 36(1), 41-57. 
Svara, J. H. (2006). Introduction: Politicians and Administrators in the Political Process - A Review of Themes and Issues in the Literature. International Journal of Public Administration, 29(12), 953-976.

Thomas, D. R. (2006). A general inductive approach for analyzing qualitative evaluation data. American Journal of Evaluation, 27(2), 237-246.

Toma, J. D., Dubrow, G. and Hartley, M. (2005). The Uses of Institutional Culture: Strengthening Identification and Building Brand Equity in Higher Education. ASHE Higher Education Report, Volume 31, Number 2. ASHE Higher Education Report, 31(2), $1-105$.

UNDP. (1997). Governance for Sustainable Human Development. A UNDP Policy Document. New York: United Nations Development Programme.

Vintar, M., Aristovnik, A. and Klun, M. (Eds.). (2018). Vidiki in dejavniki uspešnega izvajanja javnih politik (Aspects and factors of public policies implementation). Ljubljana: Faculty of Administration.

Volkery, A. and Ribeiro, T. (2009). Scenario planning in public policy: Understanding use, impacts and the role of institutional context factors. Technological Forecasting and Social Change, 76(9), 1198-1207, https://doi.org/10.1016/j.techfore.2009.07.009.

Woolthuis, R. K., Lankhuizen, M. and Gilsing, V. (2005). A system failure framework for innovation policy design. Technovation, 25(6), 609-619.

Workman, S., Jones, B. D. and Jochim, A. E. (2009). Information Processing and Policy Dynamics. The Policy Studies Journal, 37(1).

Xie, X., Zeng, S., Peng, Y. and Tam, C. (2013). What affects the innovation performance of small and medium-sized enterprises in China? Innovation, 15(3), 271-286.

Yin, R. K. (2017). Case study research and applications: Design and methods. Los Angeles: Sage publications.

Zito, A. R. (2015). Expertise and Power: Agencies Operating in Complex Environments. Politics and Governance, 3(1), 73-89, https://doi.org/10.17645/pag.v3i1.81. 